\title{
Synthesis of $\alpha$-collagen fragments and research of their influence on the degree of hydration of a model of epidermis
}

\author{
Beata Łubkowska', Beata Grobelna², Zbigniew Maćkiewicz ${ }^{1}$ \\ 1Department of Polypeptides Chemistry, Faculty of Chemistry, University of Gdansk, Poland \\ Head: Prof. Zbigniew Maćkiewicz \\ 2Department of Analytical Chemistry, Faculty of Chemistry, University of Gdansk, Poland \\ Head: Prof. Tadeusz Ossowski
}

Postep Derm Alergol 2013; XXX, 1: 6-12

DOI: 10.5114/pdia.2013.33373

\begin{abstract}
Introduction: In recent years the interest into areas of science, such as cosmetology, dermatology, pharmacology or aesthetic medicine has increased significantly. Scientists are more frequently looking for ingredients that affect the skin's condition and slow down the aging process. Practically every year, the scientists discover a number of new chemical substances (both natural and synthetic) that can be potentially used to manufacture cosmetics.

Aim: To evaluate the influence of selected peptides derived from $\alpha$-collagen fragments on the degree of hydration of a model of epidermis isolated from a pig.

Material and methods: The synthesis of selected cosmetic oligopeptides were performed manually, on the solid medium, using procedure of SPPS (solid phase peptide synthesis). Following components: aqua, carbomer, glycerine, phenonip, D-panthenol, dimethicone and triethanolamine were used to prepare a reference hydrogel masks. Both the number of components and the composition of hydrogels have been developed individually for the purposes of this research. For this study the skin from a domestic pig was used. The degree of the skin hydration was measured with the SKINTEST plus camera, which uses the latest semiconductor technology.

Results: During the study the absorption of hydrogels with peptides was faster than that of the reference hydrogel mask. The combination of hydrophilic properties of the peptide with hydrophobic properties of Palm enabled receiving an amphiphilic structure. Such molecules are considered to be able to penetrate the corneum barrier with the greatest ease.

Conclusions: The results showed that the modified compounds have contributed to water retention in the cells, thereby increasing the degree of hydration of the biological material.
\end{abstract}

Key words: synthesis, collagen, peptides, model epidermis, proliferation, skin hydration.

\section{Introduction}

Collagen is a protein that is most prevalent in mammals and it is located almost all over the body, constituting $1 / 3$ of the mass of all proteins. In the skin it amounts to approximately $70 \%$ of the proteins' mass [1]. A collagen molecule, often called tropocollagen, consists of three subunits, each of which turns left every three amino acid residues. The three chains create a clockwise spiral, which is called a triple helix structure [2]. The triple helix is a tightly packed structure, through covalent and hydro- gen bonds formed by L-hydroxylysine and L-hydroxyproline. In building the structure of this protein, depending on the genetic type and origin, from 19 to 21 amino acids are involved [3]. Construction of collagen is based on the structure defined by the formula: (X-Y-Gly) ${ }_{n}$, in which every third amino acid residue is glycine. Glycine (Gly) as a small amino acid is able to fit in the center of the spiral, at the junction of three chains. Other amino acids which are marked with symbols $X$ and $Y$ in the formula, are usually Pro (L-proline) or Hyp (4-L-hydroxyproline) and they constitute approxi-

Address for correspondence: Beata Łubkowska PhD, Department of Polypeptides Chemistry, Faculty of Chemistry, University of Gdansk, 18/19 Sobieskiego Str., 80-952 Gdansk, Poland, phone: +48 5852354 12, e-mail: b.lubkowska@gmail.com Received: 1.08.2012, accepted: 12.11.2012. 
mately $20 \%$ of the collagen molecule. Collagen consists also of L-arginine, L-glutamic acid, L-serine and L-5-hydroxylisine. The presence of L-hydroxyproline affects the thermal stability of collagen, whereas the stereo-electron effects are responsible for stabilization of the collagen molecule. The presence of an additional hydroxyl group at position $Y$ enables forming of hydrogen bonds between water molecules. A single chain of collagen contains about 1000 amino acid residues, forming a molecule with a length of $300 \mathrm{~nm}$. However, the quantitative composition of collagen depends on the age of the mammal and the type of tissue it is a part of $[1,4,5]$.

The young collagen which is present in the body, which is obtained through biosynthesis, is soluble in aqueous buffers. Therefore, only this form is responsible for maintaining adequate water content in the skin. Skin aging is caused by the progressive transformation of soluble collagen in the insoluble form of collagen through cross-linking reactions and the constitution of proteins, which have less capacity to retain water. Collagen's ability to swell in acid solutions and its susceptibility to enzymes decreases with age. During our life the stiffness of fibers increases, ultimately leading to their fragility as a result of decline in tensile strength. Changes of the chemical and physical properties of collagen fibers that occur in the aging process are very noticeable. The clearest symptom of the aging process of the skin is that it is wrinkled, dry and loses its elasticity [6].

In many scientific centers around the world, researchers are looking for new compounds that could affect the remodeling of skin and also enhance its ability to stop the evaporation of water from its surface [5]. The research on the role of biologically active peptides is being conducted. The peptides are divided into three groups according to their function: signal peptides, carrier peptides and neurotransmitter-affecting peptides [3]. Peptides which originate the decomposition of $\alpha$-helices belong to the collagen stimulating peptides, called signal peptides [7]. They were used for example in the renewal process of elastic fibers of the skin, due to their effect on fibroblast cell functions. Over time, fibroblast activity decreases, which results in slowing down of skin supporting protein synthesis. This is one of the factors associated with biological aging of skin, which leads to the formation of wrinkles and loss of firmness [8]. By stimulating the proliferation processes, the density of the cells increases and thus the permeability of the skin decreases. It is an indirect effect of peptides stimulating cell, which is very beneficial because it leads to an increase in skin hydration and improves its appearance $[9,10]$.

\section{Aim}

The main aim of this study was to assess the impact of synthesized peptides derived from the dissolution of helices of $\alpha$-collagen on the degree of hydration of a mod- el of pig skin. The peptides were used as components in hydrogel moisturizing masks.

\section{Material and methods \\ Material}

$\alpha$-Amino acids (AA) (glycine, L-proline, L-alanine, L-4hydroxyproline) used for chemical synthesis of peptides were obtained from Orpegen Pharma or Bachem Company and used in the form received with 9-fluorenylmethoxycarbonyl (Fmoc) protection shield. As resin, 2-chlorotrityl chloride resin (Novabiochem ${ }^{\circledR}$ ) was used. Coupling reagents were N,N'-diisopropylcarbodiimide (DIC) and N-hydroxybenzotriazole (HOBt) (Acrōs Organics). The organic compounds used in synthesis were N,N-diisopropylethylamine (DIPEA or DIEA) (Sigma-Aldrich $\left.{ }^{\circledR}\right), N, N$-dimethylformamide (DMF), dichloromethane (DCM), methanol (MeOH) (POCH SA), piperidine (Sigma-Aldrich) and palmitic acid (VO SOIUZCHIMEXPORT). The following were also used: trifluoroacetic acid (TFA) (Acrōs Organics), acetonitrile (ACN) (Lab-Scan analytical sciences), triisopropylosilane (TIPS) (Alta Aesar), butanol $(\mathrm{BuOH})$, ethanol $(\mathrm{EtOH})$, ammonia $\left(\mathrm{NH}_{3}\right)(\mathrm{POCH} \mathrm{SA})$, salicylic acid (Amara Sp. z o.o.), acetic acid (Przedsiębiorstwo Chemiczne Odczynniki Sp. z o.o.), ethyl acetate (EtOAc) (Chempur ${ }^{\circledR}$ ). Excipients were acetaldehyde, chloranil (Fluka), diethyl ether $\left(\mathrm{Et}_{2} \mathrm{O}\right)$ (Chempur $\left.{ }^{\circledR}\right)$.

The hydrogel mask was prepared from the following ingredients [INCI]: Aqua, Carbomer (Carbopol ${ }^{\circledR}$ Ultrez 10) (Lubrizol, S\&D Poland), Glycerin, Triethanolamine (POCH SA), Phenonip ${ }^{\circledR}$ (Clariant UK Ltd.), D-Panthenol (Standard Sp. z o.o.), Dimethicone (Silicon DC 193) (Clariant UK Ltd., Arnand Polska).

\section{Procedure of synthesis}

The synthesis of selected cosmetic oligopeptides with the following sequences: Pal-Gly-Gly-Pro-Ala-Gly, Pal-GlyGly-Pro-Gly-Ala-Pro and Pro-Ala-Gly-Hyp-Pro was performed manually, on the solid medium, using the procedure of SPPS - Solid Phase Peptide Synthesis [11].

\section{Preparation of resin}

$0.5 \mathrm{mg}$ 2-chlorotrityl chloride resin $(0.9-1.3 \mathrm{mmol} / \mathrm{g}$, $1 \mathrm{~g})$ was used for the synthesis of each peptide. The resin was shaken for 90 min with a Laboratory Shaker- Type 3585 (Elpan) with amplitude 6, and speed of 90-100 c.p.m.

\section{Joining the first $\alpha$-amino acid}

The synthesis was conducted on the C-terminus of the peptide. To an activated resin, 1 molar equivalent (eq) of AA was added, which was dissolved in a mixture of DMF : DCM $(1: 1 \mathrm{v} / \mathrm{v})$. Into the vessel, a fourfold excess of DIPEA was added and the mixture was shaken for $120 \mathrm{~min}$. Following this, the resin was filtered off and washed three times with a mixture of DCM : methanol : DIPEA (17: $2: 1$ 
$\mathrm{v} / \mathrm{v} / \mathrm{v}$ ) after 5, 15 and 30 min to block the free linker on the resin.

In order to calculate the actual degree of the precipitation, the first AA resin was filtered off and dried in a vacuum desiccator until it was brought to constant weight.

\section{Elongation of the peptide chain}

Elongation of the peptide chain was based on deprotection and acylation reactions. The reaction of activation of $\alpha$-carboxyl group of $N$-protected amino acids was carried out using high purity coupling agents: DIC and HOBt using a threefold excess of AA. The acylation reaction lasted $120 \mathrm{~min}$, and then the resulting mixture was washed according to the scheme: DMF $(3 \times 2 \mathrm{~min}), \mathrm{DCM}$ : DMF $(3 \times 2 \mathrm{~min})$ and DCM $(3 \times 2 \mathrm{~min})$.

The reaction of removing the Fmoc from the $\alpha$-amino group of the amino acid was performed with $25 \%$ piperidine in DMF for 5 and 15 min. After deprotection a longer cycle of washes was performed, according to the scheme: DMF, DCM : DMF, DCM, DMF, DCM : DMF, DCM, repeated every $3 \times 2 \mathrm{~min}$.

Each coupling reaction was monitored by means of the chloranil test (4 $\mathrm{ml}$ acetaldehyde in $19.6 \mathrm{ml}$ of DMF and $0.14 \mathrm{~g}$ chloranilin DMF $7 \mathrm{ml}$ ) $[12,13]$. A few grains of resin were collected into a glass tube with a pipette. One drop of a solution of acetaldehyde and 1 drop of a solution of chloranil were added to the resin. After $15 \mathrm{~min}$, the color of granules was rated. Once the beans of the resin were green, meaning Fmoc was removed, the process of synthesis continued.

\section{Removed peptide from resin}

The protected peptidyl resins were treated with $10 \mathrm{ml}$ of a solution of: TFA : TIPS : $\mathrm{H}_{2} \mathrm{O} 9.5: 0.25: 0.25 \mathrm{ml}$ at room temperature and shaken for $120 \mathrm{~min}$ [14]. Then, the resins were filtered off on a Schott funnel, washed two times additionally with $1 \mathrm{ml}$ of TFA. The crude peptides were precipitated from the solution with $\mathrm{Et}_{2} \mathrm{O}$ cooled in dry ice.

Then, ether was evaporated using vacuum evaporator ROTAVAPOR-R No.35 INOX W-251 (Büchi, Switzerland) at maximum temperature $40^{\circ} \mathrm{C}$.

The last products were dried with FreezeDryer SuperModulyo at $-20^{\circ} \mathrm{C}$ and a pressure of $40 \mathrm{mbar}$.

\section{Purification of peptides}

Peptides were purified by solid-phase extraction (SPE) using LC-18 Silica-Based Packing (Sigma-Aldrich Co.) [15]. Columns were prepared by transferring at $0.1 \%$ TFA in acetonitrile (ACN) - 5 times for $10 \mathrm{ml}$, then $0.1 \%$ TFA in ACN and $0.1 \%$ TFA in water $(1: 1 \mathrm{v} / \mathrm{v})-5$ times for $10 \mathrm{ml}$ and $0.1 \%$ TFA in water also 5 times for $10 \mathrm{ml}$. Each time $100 \mu \mathrm{l}$ of the peptide was added to the mixture. As a liquid phase we applied a linear gradient from $0-100 \%$ of phase B (phase A: $0.1 \%$ TFA in water, phase B: 0.1\% TFA in ACN). After separation the columns were regenerated by washing 5 times for $10 \mathrm{ml}$ of $0.1 \%$ TFA in ACN, 5 times for $10 \mathrm{ml}$ of $\mathrm{MeOH}$ and 5 times for $10 \mathrm{ml}$ for $0.1 \%$ TFA in water.

\section{Characterization of properties}

Homogeneity of obtained fractions was tested using analytical technique - thin layer chromatography (TLC). On the glass slides coated with $0.25 \mathrm{~mm}$ layer of silica gel Kieselge 160 (Merck) a drop of an aqueous solution of AA and peptides were applied with a glass pipette, at a distance of $10 \mathrm{~mm}$ from the edge of the slide and from each other. In order to develop the chromatograms, the following systems were used: $\mathrm{BuOH}$ : acetic acid : water (BAW $4: 1: 5 \mathrm{v} / \mathrm{v} / \mathrm{v})$ and EtOAc: EtOH : $\mathrm{NH}_{3}(20: 12: 8: 2 \mathrm{v} / \mathrm{v} / \mathrm{v} / \mathrm{v})$. Chromatograms were induced by iodine vapor and using a solution of ninhydrin [16].

Indication of the molecular ion was made using universal analytical technique - mass spectrometry (MS), specifically MALDI-TOF MS (mass spectroscopy of laser desorption ionization in the matrix) on the mass spectrometer Biflex type III (BRUKER). This technique is based on the ionization of molecules and subsequent detection of ions in the electrolyte as a function of their mass-to-charge ratio $(\mathrm{m} / \mathrm{z})$ [17]. As a matrix, $\alpha$-cyano hydroxycinnamone acid (CCA) was used. As a result of the mass spectrometry, mass specters were obtained.

Analysis of the structure of peptides was performed using infrared spectroscopy (IR), in which infrared radiation is used. On the basis of registered spectra using spectrophotometer Spectrum ${ }^{\text {TM }}$ RX and FX-IR (Perkin Elmer, USA) using a potassium bromide pellet $(\mathrm{KBr})$ functional groups of compounds were determined [18].

\section{Formulation of hydrogels}

Following components: phase A (94.30\% wt. of Aqua, $0.6 \%$ wt. of Carbomer), phase B (2.0\% wt. of Glycerin, $0.3 \%$ wt. of Phenonip), phase C (0.1\% wt. D-Panthenol, 0.3\% wt. of Dimethicone) and phase D (0.4\% wt. of Triethanolamine) were used to prepare reference hydrogel masks. Both the number of components and the composition of hydrogels have been developed individually for the purposes of this research.

On the basis of the aforementioned recipe, three hydrogel masks with an additional component (0.05\% wt. of Peptide) were attained, previously obtained through chemical synthesis. Peptide was incorporated into components from phase $C$.

Every time $50 \mathrm{mg}$ of hydrogel masks were obtained, which were prepared with the following technique: carbomer was dispersed in water by gently scattering it on the surface of water, allowing it to be moisturized (for at least 10 min, while observing the behavior of carbomer), then briefly mixed. Ingredients of phase B were added and mixed thoroughly using a mechanical stirrer Eurostar Digital (Mischen IKA) at a low speed for 20 min. Then, D-panthenol with silicone was added (and peptide dissolved in 
water in the case of hydrogels including peptide). Subsequently everything was thoroughly stirred for $10 \mathrm{~min}$. Value of $\mathrm{pH}$ was checked and at the final stage triethanolamine was added until the $\mathrm{pH}$ reached about 6 . In this process no dye nor fragrance was used. Finished products were tightly sealed and stored in the fridge at $5^{\circ} \mathrm{C}$

\section{Preparation of model skin}

For this study the skin from a domestic pig was used, which came from the sides and the legs of the animal. Tissue for research was obtained from the Meat Plant immediately after the slaughter of the animal. Skin used for testing was a dead tissue. On its surface there were dead skin cells-corneocytes, which, like in the human epidermal, build the stratum corneum [19].

The epidermis has been properly prepared one hour before measurements of the hydration degree. The experiment started from cleaning the tissue and separating the tissues from the bones. Then, epidermis was shaved and cut into pieces with dimensions of $4 \mathrm{~cm} \times 5 \mathrm{~cm}$ and $2 \mathrm{~cm}$ $\times 3 \mathrm{~cm}$. To remove excess moisture from its layer, the skin was placed in a thermal dryer SUSLAB-PLE-419 (Adverti) with temperature control. It underwent four sessions, each lasting $10 \mathrm{~min}$ at $60^{\circ} \mathrm{C}$. Then, the model was disinfected with a solution of $2 \%$ salicylic acid.

Finally, tests of the hydration degree were performed for each of the hydrogel masks. Measurements were conducted for the reference hydrogel five times each on a different piece of the epidermis. Tests on hydrogels containing a specific sequence of the peptide were performed similarly, using a series of five times repetitions at a given time.

\section{Measurements of skin hydration}

The degree of the skin hydration was measured with the SKINTEST plus camera (BIOtronic). The camera uses the latest semiconductor technology. The water content of the skin model defined on the basis of luminous diodes scaled in relative terms from $1 \mathrm{~ms}$ to $20 \mathrm{~ms}$. The degree of hydration was examined before and after the application of preparations on the dissected and disinfected pieces of porcine skin. The degree of hydration was measured in the following intervals: 10, 15, 30 and $60 \mathrm{~min}$. All measurements were performed in the laboratory in neutral conditions of humidity and temperature.

The first measurements were taken before applying the hydrogel masks. A passive electrode was being attached to a piece of model skin, and the probe determining the degree of hydration was applied to the same place. The reading was carried out within 2-3 s after direct contact of the test probe with the surface of the skin. The range of the camera display was $10 \mathrm{mS}$, which indicates normal hydration of the skin.

Then, the following ingredients were applied with spatulas onto the surface of epidermis: the hydrogel mask which was the reference, hydrogel mask with Palm-Gly-GlyPro-Ala-Gly, hydrogel mask with Palm-Gly-Gly-Pro-GlyAla-Pro and hydrogel mask with Pro-Ala-Gly-Hyp-Pro. After 10 min, a series of measurements of the hydration degree was carried out. Before applying the electrodes and the test probe to the tissue, the surface was purified from residue of the unabsorbed cosmetic with a wipe. The procedure was performed once. The degree of hydration was in the range of 15-16 mS. Subsequent measurements were made every 15, 30 and 60 min, incorporating the technique described above.

\section{Statistical analysis}

Descriptive statistics with experimental methods were used [20]. The applied measurement method was sufficiently precise and sensitive. The arithmetic mean of the experimental results was calculated:

$$
\bar{x}=\frac{x_{1}+x_{2}+\ldots+x_{n}}{n}
$$

where: $x_{1,2}$ - value of the particular measurement, $x_{i}$-the value of the $i$-th measurement, $n$ - number of all measurements and the standard deviation (dispersion) scheduled according to the formula:

$$
\sigma=\sqrt{\frac{1}{n-1} \sum_{i=1}^{n}\left(x_{i}-\bar{x}\right)^{2}}
$$

The results are statistically significant. For the statistical analysis, MS Excel was used [21].

\section{Ethical aspects}

In the opinion of the Bioethical Commission of the Medical University of Gdansk, the study did not require any special authorization. Material for cosmetic testing was from lifeless porcine skin, which was purchased from the Meat Plant after slaughter and pre-treatment.

\section{Results and discussion}

During mass spectra analysis (MS), molecular weight of each peptide and signals were determined, which corresponded to pseudo molecular ions $[\mathrm{M}+\mathrm{H}]^{+}$and alkali metals adducts: $[\mathrm{M}+\mathrm{Na}]^{+},[\mathrm{M}+\mathrm{K}]^{+}$of analyzed oligopeptides. On the basis of the weight of the peptides the performance of the conducted syntheses was calculated. The data are summarized in Table 1.

Homogeneity of received fractions was verified with the TLC technique. From the chromatograms, coefficients $R_{f}$ of obtained compounds were calculated, that is: the ratio of the distance traveled by the substance being separated to the distance traveled by the head of the eluent (developing system) [22]. The characteristics are shown in Table 1. 
Table 1. Physico-chemical properties of peptides

\begin{tabular}{|c|c|c|c|c|c|}
\hline \multirow[t]{2}{*}{ Sequences of peptide } & \multicolumn{2}{|c|}{ Ion mass } & \multirow[t]{2}{*}{ Peptide mass [mg] } & \multirow[t]{2}{*}{ Productivity [\%] } & \multirow[t]{2}{*}{ TLC Rf } \\
\hline & Calculated & Designated & & & \\
\hline Pal-Gly-Gly-Pro-Ala-Gly & 595 & $634.1[M+39]$ & 219 & 76 & 0.41 \\
\hline Pal-Gly-Gly-Pro-Gly-Ala-Pro & 692 & $731.7[M+39]$ & 1002 & 89 & 0.36 \\
\hline Pro-Ala-Gly-Hyp-Pro & 453 & $\begin{array}{c}454.3[M+1] \\
476.3[M+23]\end{array}$ & 123 & 68 & 0.29 \\
\hline
\end{tabular}

Table 2. Characteristics of IR spectra for obtained peptides

\begin{tabular}{|c|c|c|c|c|c|c|c|c|}
\hline $\begin{array}{l}\text { Elements of } \\
\text { structure }\end{array}$ & $\begin{array}{c}\mathrm{NH} \\
\text { diluted }\end{array}$ & $\begin{array}{c}\mathrm{CH} \\
\text { diluted }\end{array}$ & $\begin{array}{l}\mathrm{C}=\mathrm{O} \\
\text { diluted }\end{array}$ & $\mathrm{NH}$ def. & $\begin{array}{l}\mathrm{CH}_{3} \text { def. } \\
\mathrm{CH}_{2} \text { def. }\end{array}$ & $\begin{array}{l}\text { C-Cdiluted } \\
\text { CH def. }\end{array}$ & C-Ndiluted & $\mathrm{CH}_{3}$ def. sym. \\
\hline Band range $\left[\mathrm{cm}^{-1}\right]$ & $3500-3000$ & $2965-2850$ & $1700-1650$ & $1650-1500$ & About 1460 & $1340-1100$ & $1360-1030$ & About 1380 \\
\hline \multicolumn{9}{|c|}{ Designated band $\left[\mathrm{cm}^{-1}\right]$} \\
\hline $\begin{array}{l}\text { Pal-Gly-Gly-Pro- } \\
\text { Ala-Gly }\end{array}$ & $\begin{array}{l}3315.8 \\
3086.3\end{array}$ & 2850.6 & - & 1555.3 & 1463.5 & $\begin{array}{l}1276.4 \\
1257.0\end{array}$ & $\begin{array}{l}1208.3 \\
1030.3\end{array}$ & 1381.2 \\
\hline $\begin{array}{l}\text { Pal-Gly-Gly-Pro- } \\
\text { Gly-Ala-Pro }\end{array}$ & $\begin{array}{l}3311.5 \\
3080.7\end{array}$ & 2850.6 & 1706.1 & $\begin{array}{l}1635.4 \\
1554.5\end{array}$ & 1463.4 & $\begin{array}{l}1275.4 \\
1255.9\end{array}$ & $\begin{array}{l}1172.7 \\
1030.8\end{array}$ & 1381.3 \\
\hline Pro-Ala-Gly-Hyp-Pro & $\begin{array}{l}3304.3 \\
3085.4\end{array}$ & 2867.9 & 1660.1 & 1552.9 & 1460.4 & $\begin{array}{l}1331.6 \\
1169.6\end{array}$ & 1057.4 & 1387.1 \\
\hline
\end{tabular}

Table 3. Results of measurements of hydration degree for a model of pig skin by camera SKINTEST plus

\begin{tabular}{|c|c|c|c|c|c|}
\hline \multirow[t]{2}{*}{ Skin hydration degree [a.u.] } & \multicolumn{5}{|c|}{ Time } \\
\hline & Before $^{*}$ & After $10 \mathrm{~min}^{*}$ & After $15 \mathrm{~min}^{*}$ & After $30 \mathrm{~min}^{\star}$ & After $60 \mathrm{~min}^{*}$ \\
\hline Reference hydrogel mask without peptide & $10.2 \pm 0.45$ & $15 \pm 0.71$ & $16 \pm 0.71$ & $13 \pm 0.71$ & $12 \pm 1.22$ \\
\hline $\begin{array}{l}\text { Hydrogel mask with peptide } \\
\text { Palm-Gly-Gly-Pro-Ala-Gly }\end{array}$ & $10 \pm 0.00$ & $15 \pm 0.71$ & $15.2 \pm 0.84$ & $15.2 \pm 0.45$ & $15 \pm 0.00$ \\
\hline $\begin{array}{l}\text { Hydrogel mask with peptide } \\
\text { Palm-Gly-Gly-Pro-Gly-Ala-Pro }\end{array}$ & $10.2 \pm 0.45$ & $16 \pm 1.00$ & $19 \pm 0.71$ & $17 \pm 0.71$ & $15 \pm 1.00$ \\
\hline $\begin{array}{l}\text { Hydrogel mask with peptide } \\
\text { Pro-Ala-Gly-Hyp-Pro }\end{array}$ & $10 \pm 0.00$ & $16 \pm 0.71$ & $16 \pm 0.00$ & $15 \pm 0.71$ & $14 \pm 0.71$ \\
\hline
\end{tabular}

The range of characteristic bands for the functional groups of received peptides were determined and designated on the IR. Therefore, the structure of the peptides analyzed was confirmed and identified. The results are presented in Table 2.

In addition, measurements of skin hydration before and after application of hydrogels were conducted on the prepared biological material from pig. The measurements were performed by camera SKINTEST plus. The results are depicted in Table 3 and on Figures 1-3. The table shows the measured values, on the basis of statistical measurements. Figures represent the measurements made for the hydrogel mask with peptide in relation to the referential hydrogel. The first bar chart is presented for the average values of measurements taken for the reference mask. The second bar chart shows the mean values of the measurements obtained respectively for: the hydrogel mask with Palm-Gly-
Gly-Pro-Ala-Gly, hydrogel mask with Palm-Gly-Gly-Pro-GlyAla-Pro, and the hydrogel mask of Pro-Ala-Gly-Hyp-Pro.

The physico-chemical data show that homogeneous compounds were obtained which simultaneously confirmed the correct course of peptide synthesis and all the methods used. Thus, the synthesized peptides were used as ingredients in cosmetic products in the form of hydrogel masks. Based on the statistical analysis calculated from our measurements, the impact of the additional component (peptide) on the hydration degree of the model skin in hydrogels with a specific recipe was evaluated.

Peptides from decomposition of $\alpha$-helices of collagen are peptides which can stimulate the skin cells (fibroblasts, keratinocytes) to increase production of skin protein. It improves the smoothness, elasticity and firmness, as well as the degree of hydration of the skin [3]. Results attained in this study showed that the synthesized peptides used 
in gel masks, applied to the surface of the skin model are able to improve moisture.

In the present study it should be recognized that measurements of the hydration degree were carried out on pig skin, which, although in terms of physiology is very similar to human skin, it cannot fully reflect its character. Currently, skin from a domestic swine is the best equivalent of human skin and used in numerous clinical trials. Some organs from transgenic pigs, due to the large anatomical and physiological similarities to humans, are considered a reasonable alternative for human transplantations [23]. In this experiment, the porcine skin, after suitable treatment, was used as a model tissue for cosmetics testing.

During the study the absorption of hydrogels with peptides was faster than that of the reference hydrogel mask. Furthermore, a colorless film on the surface of the skin model was observed, which over time was absorbed. A hydrogel mask containing the following peptide structures: Palm-Gly-Gly-Pro-Ala-Gly or Palm-Gly-Gly-Pro-Gly-Ala-Pro showed longer effects on the skin model. This is due to the presence of palmitic acid, which is a fatty acid of a lipophilic character. The combination of hydrophilic properties of the peptide with hydrophobic properties of palm enabled receiving an amphiphilic structure. Such molecules are considered to be able to penetrate the corneum barrier with the greatest ease [24].

The obtained results confirm that using a hydrogel cosmetic mask increases skin hydration. During testing the moisture level increased especially during the first 10 min of cosmetic applications. The higher increase in the degree of hydration was observed for the products containing peptides. With the passage of time efficiency of the hydrogel masks containing peptides remained constant (high), in contrast to the hydrogel reference, whose effect was short-lived. Finally, the following conclusions were formulated:

- Mask with peptide with appropriate sequences causes better moisturizing effects than the mask without peptide or in the same degree.

- Mask with peptide helps to keep a good moisture level and extends moisturizing benefits of the gel mask.

- Joint action of hydrogel masks and peptides helps to maintain a proper degree of hydration of the skin.

\section{Conclusions}

With age, the degree of hydration of the skin decreases, the skin becoming drier, rougher and losing water faster [25]. The studies have shown moisturizing effects of hydrogel masks with the added peptide from decomposition of $\alpha$-collagen helped to keep moisture in the skin model for longer. Proper hydration of the skin is very important because it improves its appearance, gives softness, smoothness and firmness [26]. The results are an unequivocal proof that masks with peptide are able to improve skin hydration provided the right recipe is chosen. It is believed

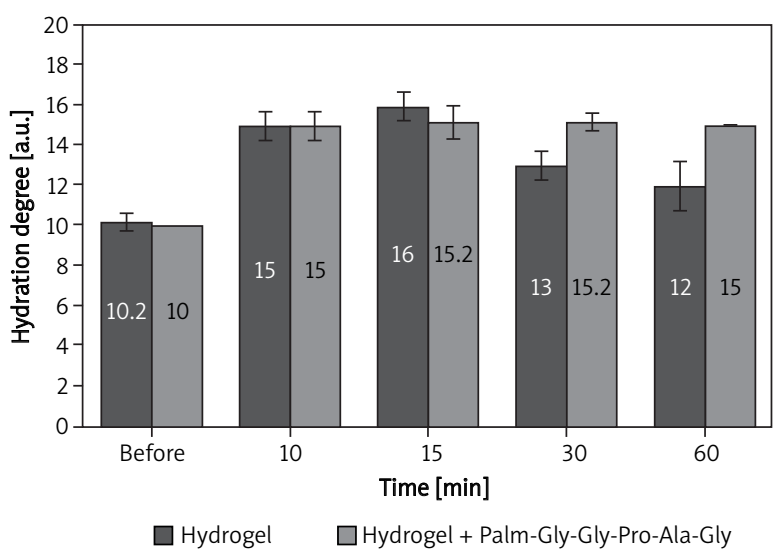

Figure 1. Measurements for the reference hydrogel and hydrogel mask with Palm-Gly-Gly-Pro-Ala-Gly

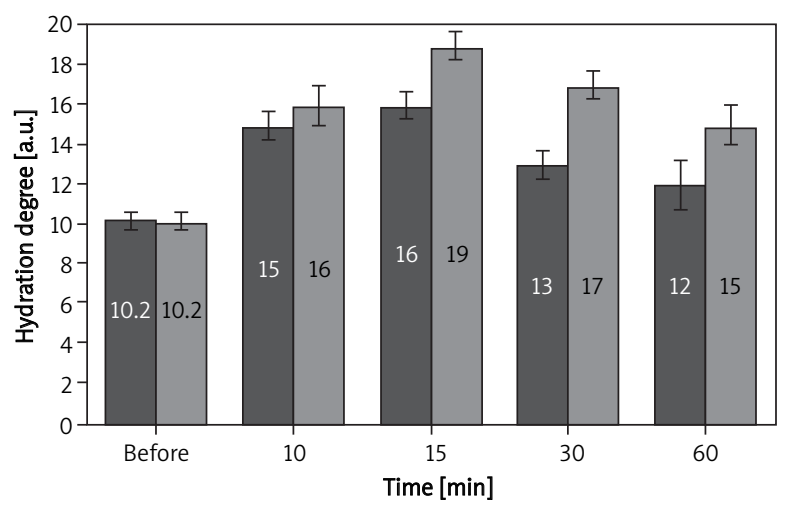

Figure 2. Measurements for the reference hydrogel and hydrogel mask with Palm-Gly-Gly-Pro-Gly-Ala-Pro

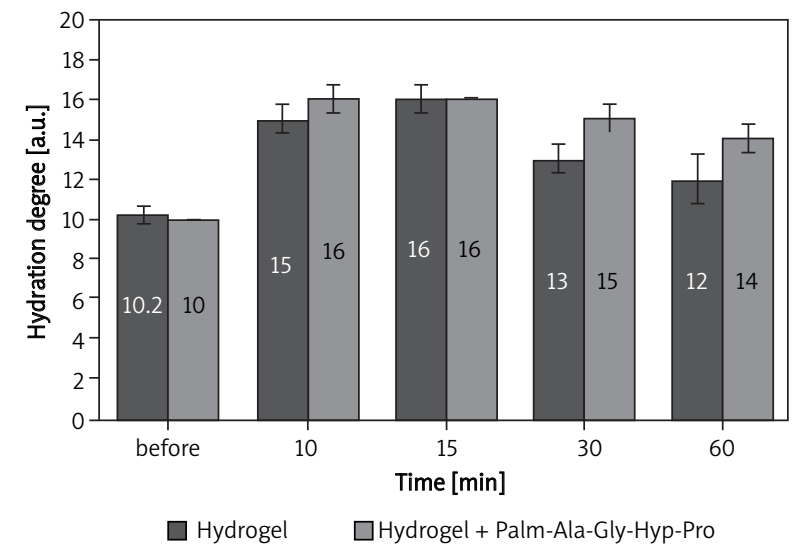

Figure 3. Measurements for the reference hydrogel and hydrogel mask with Pro-Ala-Gly-Hyp-Pro 
that regular use of hydrogel masks can permanently improve and increase the skin hydration.

\section{Acknowledgments}

This work was supported by BSR MNiUSD no. 538-84541058-12, DS/8452-4-0135-12 (Prof. Z. Maćkiewicz) and DS/8210-4-0177-12 (Dr. B. Grobelna) University of Gdansk. Many thanks to companies: S\&D and Arnand Poland for a great cooperation and provision of the necessary substances for the preparation of cosmetics.

\section{References}

1. Gelse K, Poschl E, Aigner T. Collagens - structure, function, and biosynthesis. Adv Drug Deliv Rev 2003; 55: 1531-46.

2. Pytkowska K, Arct J. Active ingredients in anti-aging cosmetics. Dermatol Estet 2009; 2: 144-7.

3. Lupo MP, Cole AL. Cosmeceutical peptides. Dermatol Ther 2007; 20: 343-9.

4. Łubkowska B, Grobelna B, Maćkiewicz Z. The use of synthetic polypeptides in cosmetics. Copernican Letters 2010; 1: 75-82.

5. Lupo MP. Cosmeceutical peptides. Dermatol Surg 2005; 31: 832-6.

6. Banieczko SA, Liedzjewirow AM. Collagen. A new strategy to extend the health and youth [Polish]. Publisher Hobbit Plus, Koleczkowo 2010.

7. Katayama K, Armendariz-Borunda J, Raghow R. A pentapeptide from type I procollagen promotes extracellular matrix production. J Biol Chem 1993; 268: 9941-4.

8. Jaroszewska B. Cosmetology [Polish]. Athena, Warsaw 2008.

9. Griffiths TW. Cosmeceuticals coming of age. Br J Dermatol 2010; 162: 469-71.

10. Lee C.H, Singla A, Lee Y. Biomedical applications of collagen. Int J Pharmac 2001; 221: 1-22.

11. Barlos K, Application of 2-chlorotrityl resin in solid phase synthesis of (Leu15)-gastrin I and unsulfated cholecystokinin octapeptide. Int J Peptide Protein Res 1991; 37: 513-20.

12. Carpino LA, Han GY. Solid-phase peptide synthesis using mild base cleavage of Nalpha-fluorenylmethyloxycarbonylamino acids, exemplified by a synthesis of dihydrosomatostatin. J Am Chem Soc 1970; 92: 5749.

13. Margler M, Durieux JP. The Bachem Practice of SPPS, Bachem AG 2000.

14. Christensen T. Peptides, structure and biological function. Annual Reports in Medicinal Chemistry, Vol. 14, Hess (ed.), Academic Press 1979.

15. Kamysz W, Okrój M, Łempicka E, et al. Fast and efficient puryficationpf synthetic peptides by solid-phase extraction. Acta Chromatographica 2004; 14:

16. Walczyna R, Sokołowski J, Kupryszewski G. Analysis of organic compounds [Polish]. Publisher University of Gdansk, Gdansk 1996.

17. Szczepaniak W. Instrumental methods of chemical analysis [Polish]. Polish Scientific Publishers PWN SA, Warsaw 2002.

18. Kupryszewski G, Sobocinska M, Walczyna R. Fundamentals of preparation of organic compounds [Polish]. Publisher University of Gdansk, Gdansk 1998.

19. Dylewska-Grzelakowska J. Applied cosmetics [Polish]. School and Pedagogical Publishing SA, Warsaw 1999.

20. Korcz W, Goralczyk K, Czaja K, et al. Application of statistical methods in chemical research [Polish]. Annual NIH 2008; 59: 117-29.
21. Ufnalski W, Mądry K. Excel for chemists and others [Polish]. WNT, Warsaw 2000.

22. Bakry R, Günther K, Mair D, Svec F. Monolithic porous polymer layer for the separation of peptides and proteins using thin-layer chromatography coupled with MALDI-TOF-MS. Anal Chem 2007; 79: 486-93.

23. Smorąg Z, Stomski R, Jura J, et al. Transgenic pigs as donor tissues and organs for transplantation in humans. Breeding Review 2011; 11.

24. Ruzza P, Biondi B, Marchiani A, et al. Cell-penetrating peptides: a comparative study on lipid. Affinity and cargo delivery properties. Pharmaceuticals 2010; 3: 1045-62.

25. Martini MC. Cosmetology and pharmacology of skin [Polish]. Publisher Medical PZWL, Warsaw 2007.

26. Drega S. Healthy skin. Advice for everyone [Polish]. ABA International, Warsaw 2006. 